Polymer Journal, Vol. 4, No. 6, pp 601-606 (1973)

\title{
Reaction of Nitrogen Dioxide with Nylon 66
}

\author{
Hans H. G. Jellinek, ${ }^{*}$ Rikio Yokota, and Yutaka ItoH \\ Institute of Space and Aeronautical Science, University \\ of Tokyo, Komaba, Meguro-ku, Tokyo, Japan.
}

(Received October 9, 1972)

\begin{abstract}
Chain scission of nylon 66 films due to exposure to nitrogen dioxide at a pressure of $0.5 \mathrm{mmHg}$ has been studied as a function of temperature, film thickness, and polymer morphology. The rate of random chain scission in cast polymer films is very sensitive to changes in morphology caused by small variations in solvent composition for film casting and in mode of preparation. Decrease of chain scission with film thickness indicates that diffusion of $\mathrm{NO}_{2}$ into the polymer is rate-determining. The magnitude of the energy of activation is in agreement with this finding. It is assumed that amide links in the chain folds of polymer molecules located in the interfacial region between amorphous and crystalline polymer portions are especially susceptible to chain scission, due to their strain energy.

KEY WORDS Chain Folding / Chain Scission / Diffusion / Morphology of Polymer Films / Nitrogen Dioxide / Nylon 66 / Amide Links /
\end{abstract}

In a previous study, a remarkable retardation of chain scission of nylon 66 on exposure to nitrogen dioxide was observed, depending on the solvents used for film casting. ${ }^{1}$ This retardation is due to the presence of hydrogen-bonding compounds during preparation of the nylon films, which mask the amide linkage. The chainscission reaction which takes place by $\mathrm{NO}_{2}$ was not studied in any detail.

Therefore, the present paper deals with the random chain scission which takes place on exposure of nylon 66 films to a small pressure of $\mathrm{NO}_{2}$ as function of temperature, film thickness, and polymer morphology. Even minor variations in the solvent mixture from which films are cast and in the casting conditions affect rates of chain scission, although the mechanism of scission is the same in each case where a random chainscission process takes place.

\section{EXPERIMENTAL}

\section{Apparatus}

The high-vacuum apparatus was essentially the same as the one used for the previous investigation; ${ }^{1}$

\footnotetext{
* Permanent address: Department of Chemistry, Clarkson College of Technology, Potsdam, New York 13676, U.S.A.
}

only minor modifications were made. The vacuum (ca. $10^{-5} \mathrm{mmHg}$ ) was measured with a Pirani gauge; the temperature of the trap containing condensed $\mathrm{NO}_{2}\left(\mathrm{~N}_{2} \mathrm{O}_{4}\right)$ at the desired $\mathrm{NO}_{2}$ vapor pressure $(0.5 \mathrm{mmHg})$ was monitored by a thermocouple $(\mathrm{Cr}-\mathrm{Al})$ and the temperature was continuously recorded. The temperature of the reaction vessels were kept constant by a thermostatted water bath $\left( \pm 0.02^{\circ} \mathrm{C}\right)$. The reaction vessels were connected to a $2-l$ storage vessel during exposure to nitrogen dioxide.

All exposures took place at a pressure of 0.5 $\mathrm{mmHg}$ of $\mathrm{NO}_{2}$ (temperature of the trap -61.5$-61.2^{\circ} \mathrm{C}^{2}$ ). Films were cast on microscope slides; the latter had special arrangements for fixing them telescopically into a glass rod at the bottom of each reaction vessel.

Intrinsic viscosities were measured in an Ubbelohde viscometer at $35 \pm 0.02^{\circ} \mathrm{C}$. The solvent for these measurements was in each case 90-\% formic acid plus 10-\% water. The relationship for calculating number-average molecular weights was the same as that employed in a previous study: ${ }^{1}[\eta]=3.28 \times 10^{-4} \bar{M}_{n}{ }^{0.74} \mathrm{~d} l / \mathrm{g}$.

Percentage crystallinity was measured in a DSC (Perkin-Elmer DSC-1) with values of 45 cal/g for $100-\%$ nylon. $^{3}$ 
Table I. Film preparation ${ }^{a}$ [Purified nylon 66 (Chemstrand Corp. $\left.\left.{ }^{1}\right)\right]$

\begin{tabular}{|c|c|c|c|c|c|}
\hline Solvent for casting & $\begin{array}{l}\text { Casting conditions } \\
\text { (film area } 15 \mathrm{~cm}^{2} \text { ) }\end{array}$ & Solvent vaporization & $\begin{array}{l}\text { Morphology and } \\
\text { particle size }\end{array}$ & Crystallinity, \% & Designation \\
\hline $\begin{array}{l}80-\% \text { formic acid } \\
20-\% \text { methanol }\end{array}$ & $\begin{array}{l}\text { nylon dissolved in } \\
\text { formic acid, then } \\
\text { methanol added; left } \\
\text { overnight }\end{array}$ & $\begin{array}{l}\text { evaporation time } 3-5 \\
\text { min at } 40-45^{\circ} \mathrm{C} \text {; films } \\
\text { stick poorly to glass }\end{array}$ & $\begin{array}{l}\text { transparent, partly } \\
\text { crystalline, } 10-15 \mu\end{array}$ & - & $F_{I}$ \\
\hline $\begin{array}{l}80-\% \text { formic acid } \\
20-\% \text { methanol }\end{array}$ & $\begin{array}{l}\text { mixture left for } 3 \\
\text { weeks at room } \\
\text { temperature before } \\
\text { dissolving polymer }\end{array}$ & $\begin{array}{l}\text { same as above; films } \\
\text { stick well to glass }\end{array}$ & $\begin{array}{l}\text { transparent, more } \\
\text { crystalline than } \\
\mathrm{F}_{\mathrm{I}} ;<1.8 \mu\end{array}$ & - & $\mathrm{F}_{I I}$ \\
\hline $\begin{array}{l}80-\% \text { formic acid } \\
20-\% \text { methanol }\end{array}$ & $\begin{array}{l}\text { nylon dissolved in } \\
\text { formic acid, then } \\
\text { methanol added; left } \\
\text { for about } 2 \mathrm{hr}\end{array}$ & $\begin{array}{l}\text { same as above; films } \\
\text { do not stick to glass }\end{array}$ & $\begin{array}{l}\text { transparent, partly } \\
\text { crystalline, } 15-20 \mu\end{array}$ & 一 & $F_{I I I}$ \\
\hline $\begin{array}{l}80-\% \text { formic acid } \\
20-\% \text { methylformate }\end{array}$ & same as $F_{I I I}$ & $\begin{array}{l}\text { same as above: films } \\
\text { stick to glass }\end{array}$ & $\begin{array}{l}\text { transparent, partly } \\
\text { crystalline, } 6-10 \mu\end{array}$ & 33 & $\mathrm{~F}_{I V}$ \\
\hline $\begin{array}{l}80-\% \text { formic acid } \\
20-\% \text { methanol }\end{array}$ & $\begin{array}{l}\text { nylon dissolved in } \\
\text { mixture, cast at once }\end{array}$ & $\begin{array}{l}\text { evaporation time } \\
\text { approximately } 2 \mathrm{hr} \\
\text { at room temperature } \\
\left(c a .25^{\circ} \mathrm{C}\right) \text {; films stick } \\
\text { well to glass }\end{array}$ & $\begin{array}{l}\text { milky white; partly } \\
\text { crystalline, }<1.5 \mu\end{array}$ & - & $\mathrm{F}_{\mathrm{V}}$ \\
\hline $\begin{array}{l}90-\% \text { formic acid } \\
10-\% \text { water }\end{array}$ & $\begin{array}{l}\text { nylon dissolved in } \\
\text { mixture, cast at once }\end{array}$ & $\begin{array}{l}\text { evaporation time } \\
\text { approximately } \\
2 \mathrm{hr} \text { at room } \\
\text { temperature; films } \\
\text { do not stick to glass }\end{array}$ & $\begin{array}{l}\text { milky white; partly } \\
\text { crystalline, } 7-10 \mu\end{array}$ & 34 & $\mathrm{~F}_{\mathrm{VI}}$ \\
\hline
\end{tabular}

a $[\eta]=1.63 \mathrm{~d} l / \mathrm{g}$ at $35 \pm 0.02^{\circ} \mathrm{C}$. 
Materials and Film Preparation

Formic acid (98-100\%, Nippon Rikagaku Yakuhin) and methanol were reagent grade; $\mathrm{NO}_{2}$ was obtained from Matheson Company.

Films were cast from solution onto thoroughly cleaned microscope slide. The nylon 66 was the same purified sample as that used in a previous study. ${ }^{1} \quad$ Most films weighed about $34 \mathrm{mg}$ (area of film $15 \mathrm{~cm}^{2}$ unless otherwise noted). The thickness of each film was also measured with a micrometer at several points. Details of film preparation are given in Table I. All films were dried prior to actual exposure to $\mathrm{NO}_{2}$ in the high-vacuum apparatus at $c a .10^{-5} \mathrm{mmHg}$ at $40^{\circ} \mathrm{C}$ for $48 \mathrm{hr}$.

Chain Scission as a Function of Temperature and Film Thickness

$\mathrm{F}_{\mathrm{I}}$ films (i.e., films of identical morphology) were exposed to $0.5 \mathrm{mmHg}$ of $\mathrm{NO}_{2}$ over a range of temperatures $\left(25^{\circ} \mathrm{C}, 35^{\circ} \mathrm{C}, 45^{\circ} \mathrm{C}, 65^{\circ} \mathrm{C}\right)$ as a function of time. Also, films of different thicknesses were exposed at the same $\mathrm{NO}_{2}$ pressure at $35^{\circ} \mathrm{C}$ for $24 \mathrm{hr}$. After each exposure, the reaction vessels were evacuated to remove all $\mathrm{NO}_{2}$ and to prevent continuation of chain scission.

The data are plotted as degree of degradation, $\alpha=\left(1 / \overline{\mathrm{DP}}_{n, t}\right)-\left(1 / \overline{\mathrm{DP}}_{n, 0}\right)$, vs. exposure time in Figure $1 ; \overline{\mathrm{DP}}_{n, t}$ and $\overline{\mathrm{DP}}_{n, 0}$ are the numberaverage chain lengths of the polymer at time $t$ and $t=0$, respectively. The straight lines obtained indicate a random chain-scission process $(\alpha=$

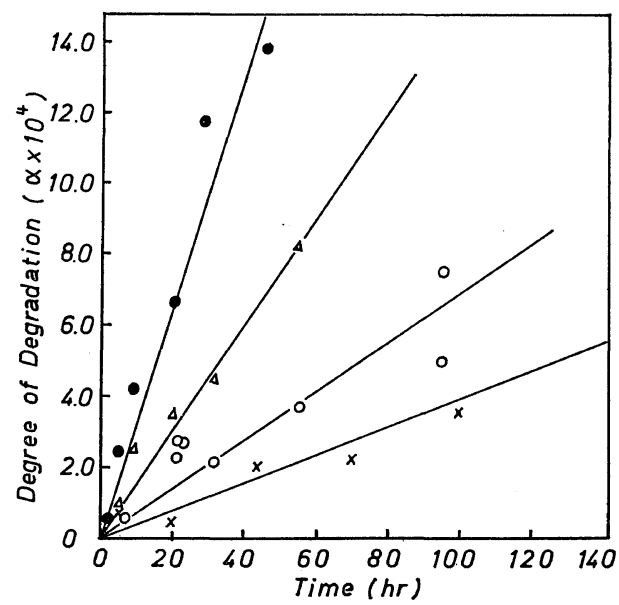

Figure 1. $\alpha$ vs. exposure time $\left(0.5 \mathrm{mmHg}\right.$ of $\mathrm{NO}_{2}$; F films):, $65^{\circ} \mathrm{C} ; \triangle, 45^{\circ} \mathrm{C} ; \bigcirc, 35^{\circ} \mathrm{C} ; \times, 25^{\circ} \mathrm{C}$.

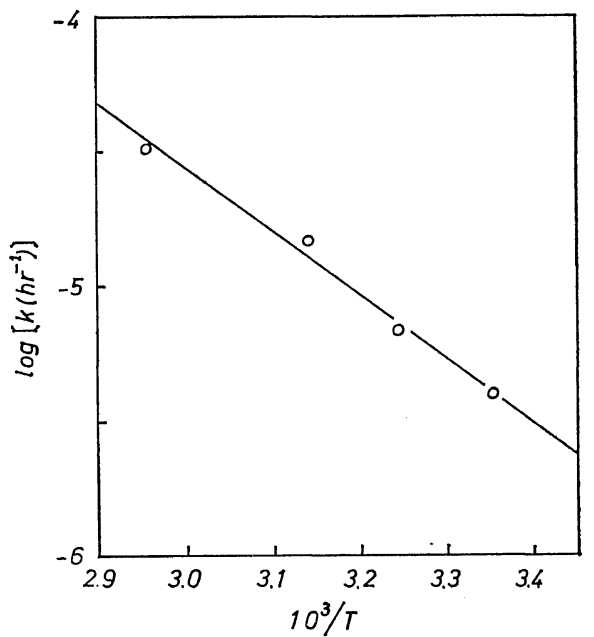

Figure 2. Arrhenius plot $\left(0.5 \mathrm{mmHg}\right.$ of $\mathrm{NO}_{2} ; \mathrm{F}_{\mathrm{I}}$ films).

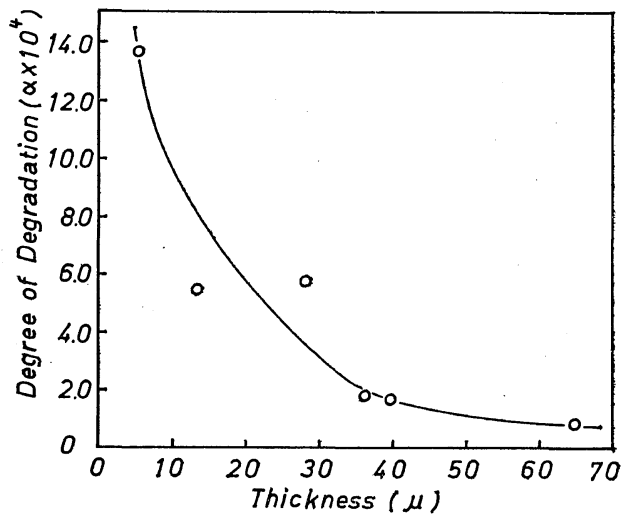

Figure 3. $\alpha$ vs. film thickness $\left(0.5 \mathrm{mmHg}\right.$ of $\mathrm{NO}_{2}$, $35^{\circ} \mathrm{C}, 24 \mathrm{hr}$ ).

$\left.k_{\text {expt1 } 1} t\right)$. Some scatter was found in the results due to difficulties in reproducing morphology exactly and due to slight variations in film weight (thickness). The straight lines have been drawn by the method of least squares.

The corresponding Arrhenius plot is shown in Figure 2 from which the following equation was derived.

$$
k_{\text {expt1 }}=3.7 \times 10^{2} \exp \left\{-10.9\left(\mathrm{kcal} \mathrm{mol}^{-1}\right) / R T\right\} \mathrm{hr}^{-1}
$$

The experimental rate constants, in order of decreasing temperature, are in $3.23,1.48,0.69$, and $0.39 \times 10^{-5} \mathrm{hr}^{-1}$, respectively. 
H. H. G. Jellinek, R. Yokota, and Y. ItoH

Table II. Effect of different film-casting conditions on chain scission ${ }^{\text {a }}$

\begin{tabular}{|c|c|c|c|c|c|c|}
\hline Film & $\begin{array}{l}\text { Solvent mixture } \\
\text { for casting } \\
\text { (FA= formic acid) }\end{array}$ & $\begin{array}{l}{[\eta],} \\
\mathrm{d} l / \mathrm{g}\end{array}$ & $\alpha$ & $\underset{\%}{\text { Crystallinity }}$ & $\begin{array}{c}\text { Particle } \\
\text { size, } \mu\end{array}$ & $\begin{array}{l}\text { Weight of film } \\
\left.\text { (area } 15 \mathrm{~cm}^{2}\right), \\
\mathrm{mg}\end{array}$ \\
\hline$F_{I}$ & $80-\%$ FA $20-\% \mathrm{CH}_{3} \mathrm{OH}$ & 1.54 & $1.9 \times 10^{-4}$ & 33 & $10-15$ & 34 \\
\hline$F_{I I}$ & $80-\%$ FA $20-\% \mathrm{CH}_{3} \mathrm{OH}$ & 1.51 & $2.5 \times 10^{-4}$ & partly cryst & $<1.8$ & 33.1 \\
\hline$F_{\text {III }}$ & $80-\%$ FA $20-\% \mathrm{CH}_{3} \mathrm{OH}$ & 1.56 & $1.4 \times 10^{-4}$ & partly cryst & $15-20$ & 34.8 \\
\hline$F_{I V}$ & $\begin{array}{l}80-\% \text { FA } 20-\% \\
\text { Methylformate }\end{array}$ & 1.55 & $1.7 \times 10^{-4}$ & $32-34$ & $6-10$ & 34.9 \\
\hline $\mathrm{F}_{\mathrm{V}}$ & $80-\%$ FA $20-\% \mathrm{CH}_{3} \mathrm{OH}$ & 0.39 & $1.4 \times 10^{-2}$ & partly cryst & $<1.5$ & 39.8 \\
\hline $\mathrm{F}_{\mathrm{VI}}$ & $90-\%$ FA $10-\% \mathrm{H}_{2} \mathrm{O}$ & 1.08 & $1.7 \times 10^{-3}$ & 34 & $7-10$ & 28.8 \\
\hline
\end{tabular}

a For details of film preparation see Table I; $0.5 \mathrm{mmHg}$ of $\mathrm{NO}_{2}, 35^{\circ} \mathrm{C}, 24 \mathrm{hr}$.

Degrees of degradation as a function of film thickness are plotted in Figure 3. The curve gives quite a good straight line by plotting $\log \alpha$ vs. thickness $\left(0.5 \mathrm{mmHg}, 35^{\circ} \mathrm{C}, 24 \mathrm{hr}\right)$.

Chain Scission as Function of Polymer Morphology

Table II shows films made under different casting conditions, which produced a variety of

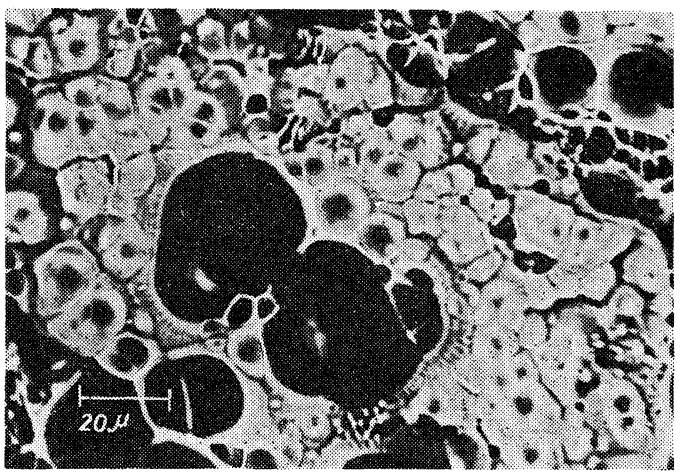

Figure 4. Optical micrograph of film I ( $\left.F_{I}\right)$ between crossed polarizers.

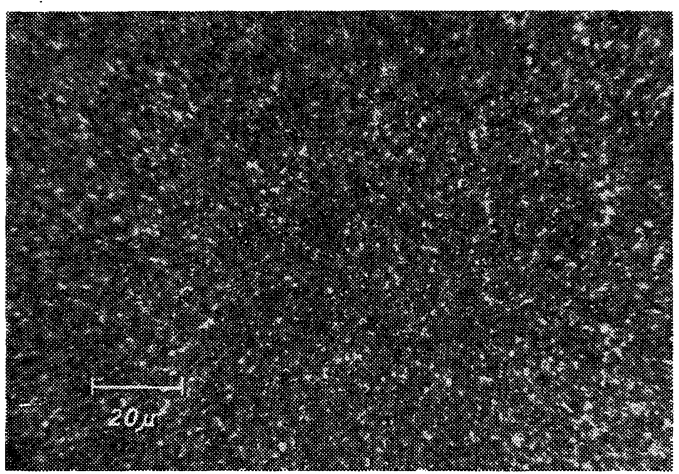

Figure 5. Optical micrograph of film II $\left(\mathrm{F}_{I I}\right)$ between crossed polarizers. morphologies $\left(\mathrm{NO}_{2}: 0.5 \mathrm{mmHg}, 24 \mathrm{hr}, 35^{\circ} \mathrm{C}\right)$.

Some typical film pictures, taken under the polarizing microscope, are shown in Figures 4-9. These pictures show that the morphology is very sensitive to slight changes in preparation and solvent composition for film casting. Although it is difficult to detect a definite trend in the $\alpha$

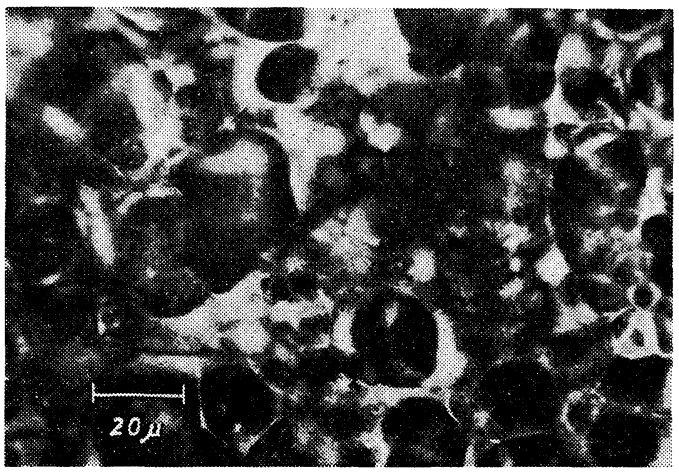

Figure 6. Optical micrograph of film III ( $\left.F_{I I I}\right)$ between crossed polarizers.

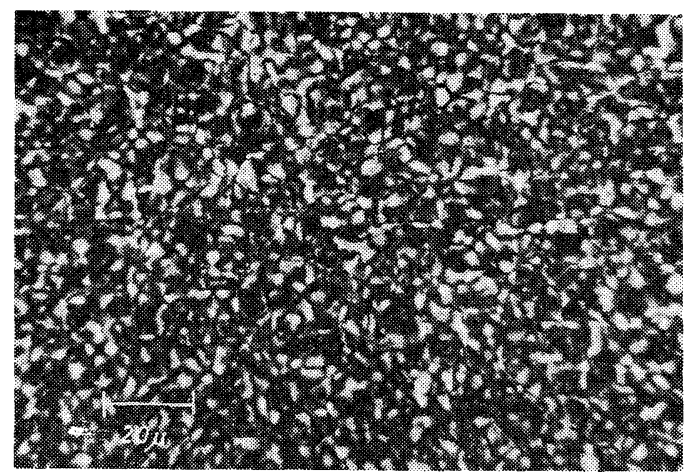

Figure 7. Optical micrograph of film IV (FIV) between crossed polarizers. 


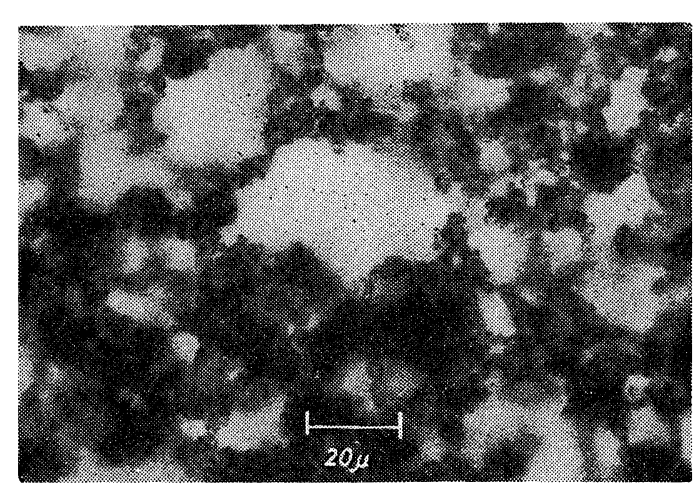

Figure 8. Optical micrograph of film $\mathrm{V}\left(\mathrm{F}_{\mathrm{V}}\right)$ between crossed polarizers.

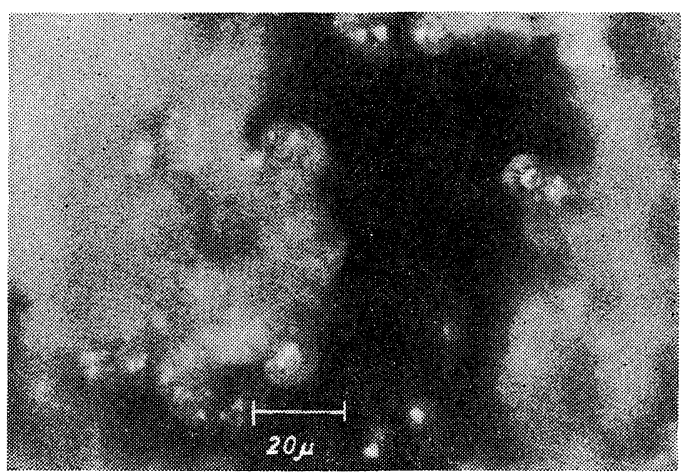

Figure 9. Optical micrograph of film VI $\left(\mathrm{F}_{\mathrm{VI}}\right)$ between crossed polarizers.

values, there seems to be an indication that for the same solvent mixture chain scission increases with decreasing particle size. Many more experiments will have to be carried out before definite trends can be recognized with any certainty.

\section{DISCUSSION}

Experiments as a function of film thickness show that diffusion of $\mathrm{NO}_{2}$ gas into the polymer film plays a decisive role in the chain-scission process. This is also indicated by the small energy of activation of $10.9 \mathrm{kcal} / \mathrm{mol}$. In a previous study ${ }^{1}$ of the nylon $-\mathrm{NO}_{2}$ reaction, energies of activation of $8.9 \mathrm{kcal} / \mathrm{mol}$ and $8.5 \mathrm{kcal} / \mathrm{mol}$ were found for the initial chain-scission reaction before complete retardation occurred. These energy of activation values agree well with the energy of activation for the diffusion coefficient of $\mathrm{NO}_{2}$-polystyrene: $(8.6 \pm 1.8) \mathrm{kcal} / \mathrm{mol}$ and
$(9.4 \pm 5.3) \mathrm{kcal} / \mathrm{mol}$ for $\mathrm{NO}_{2}$ pressures larger than $10 \mathrm{cmHg}$ and $2 \mathrm{cmHg}$, respectively. ${ }^{4}$

In each film there exists a concentration gradient with the $\mathrm{NO}_{2}$ concentration at the free film surface. Thus a definite average $\mathrm{NO}_{2}$ concentration is present in each film of a certain thickness; this average concentration decreases with increasing film thickness.

The diffusion of $\mathrm{NO}_{2}$ into polystyrene has been measured. ${ }^{4}$ Diffusion in one dimension into the polymer film, accompanied by a first-order reaction (in this case nitrogen dioxide will react with amide linkage predominantly without leading to chain scission) can be represented by an expression as follows (for details see ref 4 )

$$
\frac{\partial C_{\mathrm{NO}_{2}, X}}{\partial t}=\frac{D \partial^{2} C_{\mathrm{NO}_{2}, X}}{\partial X^{2}}-k_{\mathrm{c}} C_{\mathrm{NO}_{2}, X}
$$

$D$ is the diffusion coefficient, $C_{\mathrm{NO}_{2}, X}$ is the $\mathrm{NO}_{2}$ concentration at distance $X$ from the surface of the film and $k_{\mathrm{c}}$ is the rate constant for the accompanying reaction. If diffusion is relatively fast but slower than the chemical reaction, a steady-state concentration gradient will be established in the film. Thus there will be a constant average concentration of $\mathrm{NO}_{2}$ in the film for a constant gas pressure. The rate of change of the degree of degradation with time is then given by

$$
\frac{\mathrm{d} \alpha}{\mathrm{d} t}=k f\left(\mathrm{NO}_{2}\right)=k_{\mathrm{exp} t 1}
$$

As $f\left(\mathrm{NO}_{2}\right)=$ constant, the reaction need not necessarily be of the first order. Integration gives then the experimentally determined straight-line relationship between $\alpha$ and $t$

$$
\alpha=k_{\text {expt1 }} t
$$

The experiments with films of constant thickness obey the relation for random chain scission $\left(\alpha=k_{\text {expt1 }} t\right)$. This process can tentatively be represented as follows

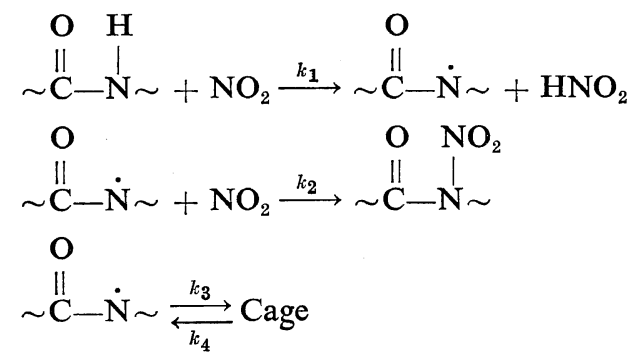




\section{Cage $\stackrel{k_{5}}{\longrightarrow}$ chain scission}

Some small molecular-weight products (i.e., $\mathrm{CO}$ and $\mathrm{NH}_{3}$ ) are probably produced during the chain-scission reaction. However, this has not as yet been investigated.

The kinetics for the random chain process can be formulated as follows

$$
-\frac{\mathrm{d}[n]}{\mathrm{d} t}=k_{5}[\text { Cage }]
$$

The steady state concentration for the cages is given as (the chain-scission reaction is negligible in this context)

$$
[\text { Cage }]=\frac{k_{3}[n]_{0}}{k_{4}}
$$

$[n]$ and $[n]_{0}$ are the concentrations of amide links at time $t$ and $t=0$ of the chain-scission process; $[n] \cong[n]_{0}$, since only a few links are broken. Hence, the rate of rupturing amide links is

$$
-\frac{\mathrm{d}[n]}{\mathrm{d} t}=k_{5} \frac{k_{3}}{k_{4}}[n]_{0}
$$

or

$$
\alpha=\frac{1}{\overline{\mathrm{DP}}_{n, t}}-\frac{1}{\overline{\mathrm{DP}}_{n, 0}}=k_{5} \frac{k_{3}}{k_{4}} t=k_{\mathrm{expt1}} t
$$

As indicated in Table II, the rate of chain scission is very sensitive to the morphology of the films or, in other words, to the mode of their preparation. Even a small amount of ester formed while the mixture of formic acid and methanol stood at room temperature has an influence on the film morphology and with it on the chainscission rate constant. The results indicate, although they are not yet numerous enough to draw definite conclusions, that chain-scission rate constants increase with decreasing particle size. It was previously found in the case of polystyrene ${ }^{5}$ that chain scission actually increases with increase in crystallinity. This was assumed to be due to strain energy in the chain folds of the crystalline regions which make the links in these folds more susceptible to chain scission than those in the straight-chain portions. This increase is counteracted by the decrease in the rate of diffusion in the crystalline regions. It is to be expected that the chain folds in the interfacial areas between crystalline and amorphous regions are especially important in this respect. The smaller the crystallites are the larger is this interfacial area and the more chain folds are accessible to the reacting gas; the smaller the crystallites are the less important will be the influence of diffusion compared with polymer films of the same percentage of crystallinity having larger crystallites. Thus, a partially crystalline polymer having small crystallites should show faster chain scission than a film of the same percentage crystallinity composed of larger crystallites. Such behavior seems to be indicated by the present experimental results. Much more work is needed before any definite conclusions can be drawn in this respect.

The observation that films, cast from formic acid-methanol (or methylformate) mixtures are transparent whereas those cast from formic acid -water mixtures are milky white, is of interest. This has some connection with the vaporization process of the solvent mixture and the accompanying mode of precipitation of the polymer.

In a previous study, ${ }^{1}$ almost complete inhibition of chain scission was observed when small amounts of hydrogen-bonding substances were present during film casting. Change in morphology as such does not have an inhibiting effect. Random chain scission takes place whatever morphology is produced, while only masking of amide links causes inhibition of chain scission.

Acknowledgment. Sincere thanks are due to Professor H. Kambe for his interest in this work and for his kind hospitality to one of the authors (H.H.G.J.) during his stay at the Institute.

\section{REFERENCES}

1. H. H. G. Jellinek and A. Chaudhuri, J. Polym. Sci., Part A-1, 10, 1773 (1972).

2. A. C. G. Egerton, J. Chem. Soc., 105, 647 (1914); see also Gmelin's Handbuch, Der Anorganischan Chemie, System 4, Lieferung 1-4, Verlag Chemie Leipzig, Berlin 1936 (1955) p. 748.

3. M. Dole and B. Wunderlich, Makromol. Chem., 34, 29 (1959).

4. H. H. G. Jellinek and S. Igarashi, J. Phys. Chem., 74, 1409 (1970).

5. P. Hrdlovic, J. Pavlinee, and H. H. G. Jellinek, J. Polym. Sci., Part A-1, 9, 1235 (1971); see also D. C. Bassett, Polymer, 5, 457 (1964). 